\title{
LENGUAJE, RAZÓN Y CIENCIA EN EL SISTEMA HOBBESIANO
}

MARta L. LUKAC DE STIER

INSTTTUTO DE FiLOSOFIA Práctica

CONICET - BUENOS AIRES

Untversidad Católica ARgentina

The most noble and profitable invention of all other, was that of speech, consisting of names or appellations, and their connexion; whereby men register their thoughts; recall them when they are past; and also declare them one to another for mutual utility and conversation; whithout which, there had been amongst men, neither commonwealth, nor society, nor contract, nor peace, no more than amongst lions, bears and wolves.

Lepiathan I, cap. 4

Del epígrafe citado surgen una serie de cuestiones que caracterizan la semántica hobbesiana mostrando la importancia del tema del lenguaje en el sistema de Hobbes. En primer lugar cabe destacar el carácter convencional y artificioso del lenguaje, al que el filósofo inglés califica como la invención más noble y provechosa. Señala a continuación las dos funciones que él le reconoce, esto es, el registro de los propios pensamientos a través de lo que Hobbes denomina "marca" o "señal" (marks) que sirve para la evocación y la comunicación con otros a quienes se manifiesta lo pensado y lo conocido a través de signos (signs). Finalmente, se pone de manifiesto la importancia del lenguaje como condición de posibilidad para la existencia de la sociedad, del contrato, del Estado y de la paz. Por añadidura, el lenguaje aparece como especificador del hombre, pues lo distingue de otros vivientes, animales no lingüísticos, que no son capaces de esas creaciones artificiales cuyo corazón artificial es el Estado. ${ }^{1}$

Trataremos a continuación de presentar escuetamente los puntos relevantes de la teoría hobbesiana del lenguaje, desarrollada de modo sintético en el Leviathan I, cap. 4 y en Human Nature cap. 5, más analíticamente en el De Corpore, en la primera parte denominada Computatio sive Logica.

1 Cfr. M. Bertman., "Semantics and Political Theory in Hobbes", en Hobbes Sudies, Van Gorcum, 1988, vol. I, pp. 134-142. 
El lenguaje se compone de palabras conectadas de tal modo que se convierten en signos de nuestro pensamiento. Hobbes define los signos como "antecedentes de sus consecuentes y los consecuentes de sus antecedentes siempre que los observemos anteponerse o bien seguirse de algo cada vez que esto ocurre" ${ }^{2}$ Pone como ejemplo las espesas nubes negras como signos de la lluvia que se seguirá como consecuencia, y la lluvia como signo de las nubes que la precedieron. Hobbes distingue entre signos naturales (natural signs), como el ejemplo recien propuesto, y signos arbitrarios (arbitrary signs) como la piedras en el camino para establecer un límite o frontera artificial.

El modo como el lenguaje sirve para remembranza de las consecuencias de causas y efectos consiste en la imposición de nombres (names-nomina) y en la conexión entre ellos. ${ }^{3}$ Es pertinente recordar que en el sistema hobbesiano todo conocimiento se reduce al conocimiento sensible. La mente humana sólo posee imágenes de las cosas sensibles, ya que la razón sólo teje relaciones entre estas imágenes sin superar el ámbito de la sensibilidad. Estas imágenes no pertenecen a las cosas mismas, son sólo efecto de la acción de ellas en nuestros sentidos. Por otra parte, para Hobbes, no hay distinción entre imagen e idea pues ésta no es más que la misma imagen que queda como mero aflojamiento de la sensación. La imagen es clara y distinta en la medida de su proximidad a la sensación, pero según se va alejando de ésta se hace cada vez más difusa e imperceptible. Retener, por tanto, en la memoria esas imágenes durante mucho tiempo no es posible. Para superar esta dificultad Hobbes apela a las marcas y señales. De este modo, el nombre es, en el sistema hobbesiano, un sustitutivo de la sensación: nos exime del contacto empírico para poder concebir la imagen. Además los nombres cumplen doble función: de marcas y de signos. Hobbes define el nombre en el De Corpore como "una palabra [word/pox humana] elegida arbitrariamente [at pleasure/arbitratu] para servir como señal [mark] que puede suscitar en nuestra mente un pensamiento similar a algún otro que hemos tenido antes, y que [disposed in speech/in oratione disposa] siendo pronunciado para otros, puede ser para ellos un signo del pensamiento que el hablante tenía o no tenía antes en su mente".

2 Todas las citas de Hobbes están referidas a la edición de Molesworth, The English Works of Thomas Hobbes (EW) y Opera Philosophica Latina (OL), 1839-1845, 2a. ed., Scientia Verlag, Londres, 1966. De Corpore, EW I, p. 14: “signs are the antecedents of their consequents, and the consequents of their antecedents, as often as we observe them to go before or follow after in the same manner".

3 Leviathan, EW III, p. 20: "the manner how speech serveth to the remembrance of the consequence of causes and effects, consisteth in the imposing of itames, and the connexion of them".

4 De Corpore, EW I, p. 16: ${ }^{\star A}$ name is a word taken at pleasure to serve for a mark, which may raise in our mind a thought like to some thought we had before, and which being pronounced to others, may be to them a sign of what thought the speaker had, or had not before in his mind.” Cfr. OL I, Pp. 13-14. 
Hago notar que coloco entre paréntesis los términos de la versión inglesa revisada por el mismo Hobbes y de la original latina, pues como acertadamente destacan Isabel Hungerland y George Vick, muchos errores de interpretación provienen de una descuidada traducción inglesa del primer manuscrito original latino. ${ }^{5}$

Unas líneas antes de dar la definición de "nombre", Hobbes había sostenido que éste sirve de "señal" antes (before) de que sea usado como "signo". Es conveniente aclarar que esa anterioridad no es temporal sino lógico-metodológica. Agrega además que los nombres, tomados solamente por sí mismos, son señales y no pueden convertirse en signos a menos que sean dispuestos y ordenados en el lenguaje como partes del mismo.

De la definición de nombre se desprende que, para Hobbes, el lenguaje es convencional. Las palabras son signos arbitrarios. El filósofo de Malmesbury supone incuestionable el origen arbitrario de los nombres cuando afirma que "si bien algunos nombres de criaturas vivientes y otras cosas usadas por nuestros primeros padres fueron enseñados por Dios mismo, aun éstos fueron impuestos arbitrariamente por Él". ${ }^{6}$ En el Leviathan sostiene que el primer autor del lenguaje fue Dios mismo, quien instruyó a Adán para ir dando nombres a las criaturas. ${ }^{7}$ Esto se compadece con otro texto del De Corpore donde Hobbes afirma que los nombres tienen su constitución no a partir de las esencias de las cosas sino de la voluntad y consentimiento de los hombres. ${ }^{8}$

Dejando de lado el empirismo gnoseológico de base y concentrando nuestra atención exclusivamente en el lenguaje podríamos aventurar, hasta aquí, que el nombre no sea algo natural sino instituido por los hombres, no aparta a Hobbes de la postura tradicional aristotélica sobre el lenguaje desarrollada en el Peri Hermeneias, y recogida posteriormente por Tomás de Aquino. Su audacia y la ruptura con la tradición se manifiesta abiertamente cuando extiende Hobbes el arbitrarismo a las primeras verdades: "Puede deducirse que las primeras verdades fueron arbitrariamente hechas por aquellos que en primer lugar impusieron los nombres a las cosas o las recibieron por imposición de otros. Pues es verdad que hombre es una criatura viviente, pero lo es porque les plugo a los hombres imponer estos dos nombres a la misma cosa $u$ objeto. ${ }^{\text {99 }}$

5 Cfr. I. Hungerland y G. Vick, "Hobbes's Theory of Signification", Joumal of the History of Philosophy, vol. XI, no. 4, 1973, pp. 459-482.

${ }^{6}$ De Corpore, EW I, p. 16: "For though some names of living creatures and other things, which our first parents used, were thaught by God himself; yet they were by him arbitrarily imposed."

7 Cfr. Leviathan, EW III, p. 18.

${ }^{8}$ Cfr. De Corpore EW I, p. 56: “ ${ }^{\circ}$ for names have their constitution not from the species of things but from the will and consent of men".

${ }^{9}$ Cfr. De Corpore EW I, p. 36. 
El alejamiento cada vez más marcado del pensamiento realista tradicional para dejar paso al escepticismo moderno se va descubriendo sucesivamente en diversos textos. En primer término: “estos nombres ordenados en el lenguaje - sostiene Hobbes - son signos de nuestras concepciones; es manifiesto que ellos no son signos de las cosas mismas, pues que el sonido de este vocablo: piedra sea el signo de una piedra, no puede ser entendido en otro sentido que en el siguiente: que aquel que lo oye colige que aquel que lo pronuncia piensa en una piedra" ${ }^{10}$ De acuerdo con el texto, si las palabras son signos de nuestras concepciones y hay un rechazo categórico de que puedan ser, aunque mediatamente, signos de las cosas, la verdad y la falsedad se convierten en atributos del lenguaje sin guardar niguna relación, ni siquiera causal, con la realidad de las cosas. Esto lleva a Hobbes a afirmar en el Leviathan: "lo verdadero y lo falso son atributos del lenguaje, no de las cosas. Y donde no hay lenguaje, no hay ni verdad ni falsedad". ${ }^{11}$

El criterio de verdad en el que Hobbes habrá de fundar sus afirmaciones no podrá consistir en la correspondencia con la cosa, ya que tal correlación, como se desprende de sus textos, es imposible de verificar por principio. Las palabras son para Hobbes los signos, en tanto tales, arbitrarios, que constituyen los marcos convencionales sobre los cuales nos ponemos de acuerdo para señalar nuestro pensamiento acerca de las cosas o los hechos. La verdad para el filósofo inglés no puede verificarse de hecho, sólo alcanzará una fundamentación de derecho, basada en la coherencia racional de las inferencias que hagamos a partir de los términos convenidos. Por este motivo Hobbes afirma en el Leviathan que "la verdad consiste en el recto ordenamiento de los nombres en nuestras afirmaciones". 12

La teoría de la verdad que se desprende de estos planteos es esencialmente analítica y tautológica, puesto que su certeza pertenece a la pura esfera de los nombres y sus relaciones sintácticas. Las palabras son condición del cálculo, o sea de la sistematicidad lógica de las nociones. El lenguaje constituye el primer grado de la ciencia, la base para el ejercicio de la razón. Por su parte la razón es, para Hobbes, una capacidad de operación formal sin contenidos propios, cuyas conexiones se establecen según una estructura que no se relaciona con la realidad. La razón no se define por sus contenidos sino por su función. Es un método, un criterio de ordenamiento sintáctico en ejercicios, que parte de

10 Cfr. De Corpore, EW I, p. 17; OL I, p. 15: "But seeing names ordered in speech are signs of our conceptions, it is manifest they are not signs of the things themselves; for that the sound of this word (vocable) stone should be the sign of a stone, cannot be understood in any sense but this, that he that hears it collects that he that pronounces it thinks of a stone."

11 Leviathan, EW III, p. 23: "true and false are attributes of speech, not of things. And where speech is not, there is neither truth nor falsehood".

12 Leviathan, EW III, p. 23: "truth consisteth in the right ordering of names in our affirmations". 
la definición unívoca del significado de sus nociones primeras. Por eso escribe en las Objectiones ad Cartesii Meditationes: "Ratiocinatio nihil aliud sit quam copulatio et concatenatio nominum sive appellationum per verbum hoc est. Unde colligimus ratione nihil omnino de natura rerum, sed de earum appellationibus. ${ }^{\text {13 }}$ Consecuentemente, en el Leviathan, Hobbes define a la razón como "el cálculo, es decir, la adición y la sustracción de las consecuencias de los nombes generales convenidos para señalar [marking] y significar [signifying] nuestros pensamientos ${ }^{\$ 14}$ Por otra parte, para el filósofo de Malmesbury la razón no es una facultad innata sino adquirida por un esfuerzo laborioso. Concretamente en el capítulo "Of Reason and Science" del Leviatban sostiene que "la razón no nace con nosotros como el sentido y la memoria, ni es obtenida por simple experiencia como lo es la prudencia; sino que se obtiene por medio del esfuerzo, primero en un correcto uso de los nombres; en segundo lugar obteniendo un método bueno y ordenado para proceder desde los elementos, que son nombres, hasta afirmaciones hechas por conexión de unos con otros; y desde allí hasta los silogismos, que son las conexiones de una afirmación con otra, hasta llegar a un conocimiento de todas las consecuencias de los nombres pertenecientes al tema tratado; y esto es lo que los hombres llaman ciencia". ${ }^{15}$

Acertadamente sostiene Bertman que para Hobbes la razón depende del lenguaje para formar los objetos de las ciencias como concepciones para entender. ${ }^{16}$ Tanta es la importancia que el lenguaje tiene en el sistema hobbesiano que el filósofo inglés llega a pensar que sin lenguaje el razonamiento es imposible. ${ }^{17}$ Alude a modo de ejemplo al clásico término $\lambda o ́ \gamma o \sigma$ que para los griegos significaba tanto verbo o palabra como razón, y agrega allí su propia interpretación lingüística del caso, ésta es: "los griegos tenían una sola palabra para ambos términos [speech and reason] no porque ellos pensaran que no hay lenguaje sin razón, sino que no hay razonamiento sin lenguaje ${ }^{78}$ En varias oportunidades Hobbes alude a la facultad de razonar como consecuencia del uso del lenguaje, lo que podríamos considerar como un antecedente, si bien remoto, de posiciones contemporáneas como la de Cassirer, que al definir al hombre como animal symbolicum, animal capaz de elaborar signos, está, en

13 Objectiones ad Cartesii Meditationes, IV, OL V, Pp. 257-258.

14 Leviathan, EW III, P. 30: "For reason, in this sense, is nothing but reckoning, that is adding and substracting, of the consequences of general names agreed upon for the marking and signifying of our thoughts."

15 Leviathan, EW III, p. 35.

16 M. Bertman, "Hobbes on language and reality", Revue Intemationale de Philosophie, no. 126,1978 , p. 536 .

17 Ibid., p. 537.

${ }^{18}$ Leviathan, EW III, p. 25. 
cierto modo, tematizando en otro contexto filosófico lo que ya se encontraba en el sistema hobbesiano.

Volviendo a la ciencia, debemos señalar que siendo producto de la razón y dependiendo ésta para Hobbes del lenguaje, también la ciencia alcanza su estatuto propio merced al uso adecuado de los nombres que constituyen el lenguaje científico. En Human Nature sostiene que "por el beneficio de los nombres nosotros somos capaces de ciencia, no así las bestias, por ausencia de ellos; ni el hombre sin el uso de los mismos". ${ }^{19}$

Las tres afirmaciones hobbesianas en torno a la que básicamente gira la relación entre lenguaje y ciencia son:

1) "las palabras verdadero [true], verdad [truth] y proposición verdadera [true proposition] son equivalentes. Pues la verdad consiste en el lenguaje, en lo dicho, y no en las cosas" [Veritas enim in dicto, non in re constitut];

2) "los nombres son signos de nuestras concepciones y no signos de las cosas mismas" [Nomina... signa sunt conceptum; manifestum est ea non esse signa ipsarum rerum];

3) "las proposiciones primarias no son más que definiciones, o partes de definiciones, y solamente éstas son los principios de la demostración, siendo las mismas verdades constituidas arbitrariamente por los inventores del lenguaje y, por lo tanto, indemostrables ${ }^{22}[. .$.$] . Pues la definición no es la esen-$ cia de ninguna cosa sino un lenguaje significativo de nuestra concepción de la cosa. ${ }^{23}$

Todas estas afirmaciones sólo pueden ser explicadas desde una determinada posición gnoseológica: el nominalismo radical de Hobbes. Ya en el inicio del De Corpore, inmediatamente después de definir la palabra como señal y como signo, clasifica los nombres en comunes y propios, señalando que el nombre común nombrando muchos individuos, uno a uno y no colectivamente, es llamado universal. En la definición de éste queda manifiesto el nominalismo que domina su pensamiento: "el término universal nunca es el nombre de algo existente en la naturaleza, ni de una idea formada en la mente, solamente y siempre es el nombre de una palabra" ${ }^{24}$

19 Human Nature, EW IV, p. 21.

20 De corpore, EW I, p. 35.

21 Ibid., p. 17.

22 Ibid., p. 37.

23 Ibid., p. 60.

24 Ibid., p. 20. 
En el Leviathan sostiene algo similar: "nada hay universal en el mundo que no sean los nombres; pues las cosas nombradas son cada una de ellas individual y singular". ${ }^{25}$

Aún más explícito es su nominalismo en Human Nature donde Hobbes sostiene que la universalidad de un nombre o palabra atribuida a muchos ha sido la causa por la que ciertos hombres, equivocadamente, pensaron en la existencia de cosas en sí mismas universales, y así, además, de Pedro y Jüan y todo el resto de los hombres que son, hayan sido o serán tales; admitieron la existencia de lo que llaman "el hombre", o bien "hombre en general", engañándose a sí mismos, pues toman la apelación general, el nombre universal por la cosa significada en él. Como prueba de su posición argumenta proponiendo pedir a un pintor que plasme en el lienzo al "hombre”, vale decir al pretendido hombre genérico o universal. Según Hobbes, lo que hará el pintor será elegir a su antojo cualquier hombre que exista, haya existido o existirá, pero ninguno de los cuales es universal. ${ }^{26}$ Podríamos objetar que el argumento hace referencia únicamente a imágenes y que no demuestra nada en el nivel de las ideas. A nuestra objección, Hobbes sólo respondería que no hay distinción entre imagen e idea, tal como expuso en el principio de su $\mathrm{Hu}$ man Nature al sostener que "esta imaginería y representación de las cualidades de las cosas es lo que llamamos cognición, imaginación, ideas, concepción o conocimiento de ellas". ${ }^{27}$

De tal modo que, para Hobbes, cuando se afirma de un viviente, una piedra, un espíritu o de cualquier cosa que es universal, sólo se está refiriendo a un nombre común y los conceptos en nuestra mente significados por estos términos son simplemente imágenes o fantasmas de varios vivientes, varias piedras, etc. Para entender la extensión de uno de estos nombres universales no necesitamos ninguna otra facultad más que nuestra imaginación, por la que recordamos que tales nombres traen a nuestra mente unas veces a unos individuos, otras veces a otros de los tantos singulares conocidos por nosotros.

Ahora bien, si al conocer que todo lo que hay en nuestras mentes son imágenes o conceptos concretos, ¿qué es lo que justifica que diferentes imágenes mentales, según Hobbes todas singulares, individuales, estén representadas por un mismo nombre universal? En otros términos, ‘cómo resuelve Hobbes el problema de que el concepto particular concreto que uno tiene en mente, distinto del concepto particular concreto que otro tiene en mente, están significados por el mismo nombre universal? La solución que Hobbes propone es la similitud. En el Leviathan afirma que "un nombre universal es

25 Laviathan, EW III, p. 21.

26 Cfr. Humun Nature, EW IV, p. 22.

27 Ibid., p. 3. 
impuesto a muchas cosas por la similitud [entre ellas] en alguna cualidad u otro accidente" ${ }^{28}$

Desde luego esta respuesta no es una solución. Para una crítica externa de la misma remito a un trabajo previo comparativo entre el valor del lenguaje en Hobbes y Tomás de Aquino; ${ }^{29}$ y para la polémica de los universales y una crítica exhaustiva del nominalismo remito a la obra Palabras, ideas, cosas de Casaubon. ${ }^{30}$

Volviendo a la pseudosolución de Hobbes, un hobbesiano como Bertman observa atinadamente que el salto entre el concepto concreto y el uso del nombre universal no queda resuelto. Intenta entonces él mismo reconstruir la solución en los siguientes términos: "la física de Hobbes considera las sensaciones como fantasmas o concepciones en la mente resultantes del movimiento de cuerpos externos sobre nuestros órganos. Esto crea movimientos cualitativos o 'accidentales' a partir de los movimientos cuantitativos de los cuerpos; la búsqueda de los objetos más allá de nuestras concepciones individuales constituye el acto científico de formular hipótesis para explicar el acontecimiento de los fenómenos. En la medida en que es científico ya estamos usando el universal. La explicación de Hobbes del origen de los universales es que los hombres simplemente recuerdan los nombres que dan a las concepciones en la mente que son similares entre sí. El nombre es siempre definible en principio, aunque Hobbes es poco claro acerca de si la definición toma en cuenta la relación 'nombre-cosa' o bien la relación 'signo-pensamiento'. Esto es lo confuso. La primera parecería proveer la denotación de los universales, la segunda su significado. La significación de los universales, la relación signo-pensamiento, depende del proceso de razonamiento [ratiocination] o de cómputo [computation] de nuestros pensamientos en la mente. Pero como las concepciones son todas particulares, el proceso de raciocinio, como acto de la mente, necesita una explicación independiente de las imágenes o fantasmas sobre los que opera. ${ }^{31}$

Este largo texto de Bertman sólo nos sirve para confirmar la imposibilidad de resolver ese salto, precisamente arbitrario, de lo individual concreto a lo universal tal como es presentado por Hobbes, quien llega a elaborar una de la teorías metodológicas más audaces y significativas de su época: el arbitrarismo cientifico. Las conclusiones a las que arriba su explicación mecanicista de los fenómenos naturales, incluyendo al individuo como ser natural, tienen un carácter hipotético. En cuanto a la fundamentación de las verdades científicas, su escepticismo lo conduce a preocuparse mucho más por la

28 Leviathan, EW III, p. 21.

29 M. Lukac de Stier, "El valor del lenguaje en Hobbes y Sto. Tomás: Coincidencias y divergencias", Philosophica, 9/10, 1987, pp. 187-196.

30 Juan A. Casaubon, Palabras, ideas, cosas, Ed. Candil, Buenos Aires, 1984.

31 M. Bertman, "Hobbes...", pp. 541-542. 
relación establecida entre el pensamiento y los signos que por la relación entre signo y realidad. Se impone señalar la separación que existe en Hobbes entre sistema lingüístico y realidad. Esta última es explicada exclusivamente en términos mecanicistas que no pueden superar lo concreto y singular. Precisamente apela al lenguaje para superar lo concreto y singular aunque sea mediante un salto no justificado. La ciencia sólo se maneja en términos universales y, para Hobbes, la universalidad sólo se da en el lenguaje, de tal modo que en el sistema hobbesiano el lenguaje se convierte en la solución para la posibilidad de la ciencia. Sin lenguaje no hay universales y sin universalidad no hay ciencia. Consecuentemente, en términos generales, la ciencia es para Hobbes una construcción o modelo lingüístico. De hecho la verdad del pensamiento se reduce al lenguaje y éste termina por convertirse en norma de toda realidad científica. 